\title{
Development of Software Package in Excel for Along and Across Wind Response of Tall Building
}

\author{
Rohan Singh Parihar ${ }^{1}, *$ Ajay Kumar Singh ${ }^{2}$ \\ ${ }^{1}$ Student $4^{\text {th }}$ semester $M$ tech. (Structure), SSGI, Junwani (BHILAI) INDIA \\ ${ }^{2}$ Assistant Professor, SSGI, Junwani (BHILAI) INDIA \\ Corresponding Author: Rohan Singh Parihar
}

\begin{abstract}
The calamitous damage to life and property due to wind storms is experienced in many parts of the world including India, which has a huge coastal area. This has embolden many investigations on the determination of wind loads on different structures. Usually the estimation of wind loads in Buildings is carried out using codes and standards, whose enumeration are generally based on wind tunnel tests performed on selected building structures with common shapes. For example in India, A draft code of IS-875 (Part 3) for wind loading gives specifications for rectangular square, cylindrical and some typical Industrial Structures. Wind pressure estimation in buildings having shapes different from that specified on codes and standard requires wind tunnel studies. Also, Wind tunnel studies are expensive in terms of resources and time. The project suggests the Dynamic analysis for determination of wind pressure (loads) in buildings and structures. MS Excel is commanding enough for the calculation of wind pressure distribution to more cases than those currently covered by limited wind tunnel data. Some comparisons were also done using STAAD Pro with the dynamic response of building considering some examples. MS Excel has been used to determine the along wind and across wind response of a tall building. A draft code CED-37 (7792) was used to generate data for the along and across wind response of a tall building by varying various parameters as height, width, depth, terrain category, basic wind speed and force coefficient for the building. Finally, calculation of response of along and across wind of any dimension of building can be done with the draft code provisions and necessity of that is discussed
\end{abstract}

Keywords: Tall Building, Along \& Across Wind Response, STAAD Pro, Spread Sheet

\section{INTRODUCTION}

Wind engineering is an upcoming field in Structural engineering. It is necessary for us to study especially for tall buildings that are prone to wind induced oscillations. In the recent times, there had been so many catastrophic damages caused by high wind speed especially in the U.S. and in the coastal regions of India which prove that many buildings that are currently in use are not fully wind resistant.

Tall buildings are common failure in these days, in both developed and developing economies and with the increase in population and lack of open spaces, instead of single storied construction, multistoried buildings are increasingly becoming popular and hence special consideration need to be given for analysis of these structures by considering the dynamic nature of wind.

As the demand for high rise, light weight and more slender structures continues to built in India, so does the importance of designing for wind induced building motion. Tall structures that meet the code for lateral drift requirements can still sway in strong wind. The recent disaster in U.S. due to hurricanes also proves that existing building are not fully wind resistant. Therefore, it becomes necessary to review the computing techniques in use for determination of along and across wind load.

It is believed that the wind load calculation will be made by taking in to account the random variation of wind speed with time \& location (terrain category) but available theoretical method have not matured sufficiently at present for use in Indian Standard Code. For this reason, static wind method of load estimation which implies a steady wind, which has to be proved to be satisfactory for normal, short and heavy structures, has been suggested.

The catastrophic damage to life and property due to wind storms is experienced in many part (hilly areas) of the world including India, which has encouraged many research on the determination of wind load (along and across) on different height structures. Usually, the evaluation of wind loads in buildings is carried out using codes and standards, whose specification are generally based on wind 
tunnel test performed on selected building structures with common shapes. For example in India, IS: 875(Part 3)-1987 gives specification for rectangular, square, cylindrical, square, cylindrical shape and some typical industrial structures. Wind pressure determination in buildings having shape different from those specified in codes and standards in codes and standards requires wind tunnel studies.

Also tall buildings will essentially respond in both the along and across wind directions. Dominating characteristic of one over the other will depend on structural characteristics, dimensions and damping. Determining along wind response is better understood and thus has a less uncertainty while across wind is largely empirical and requires wind tunnel experiments. But wind tunnel studies are very expensive in terms of resources and time.

MS Excel is potent enough to expand the solution of wind pressure determination to more cases than those currently covered by limited wind tunnel data.

\section{SPRED SHEET}

Spread sheet is initially released 30 years ago. Spread sheet is a spreadsheet developed by Microsoft for Windows, Mac OS X, Android and 2. iOS. It features calculation, graphing tools, pivot tables, and a macro programming language called Visual Basic for Applications. It has been a very widely applied spreadsheet The aim of using MS Excel is to simplify the dynamic calculations of along and across wind response for any building dimensions. In this study, comparisons of spreadsheets results with STAAD Pro has been used by taking some building models for showing the necessities of dynamic analysis.

\section{DEFINITION OF TALL BUILDING}

Tall building, Chimneys, Towers etc. are considered wind-sensitive because they are tall and slender structure and undergo wind induced oscillation in the along and across direction. Building, even though made of steel and concrete, begin to vibrate when the wind blows or an earthquake occurs. The wind sensitivity of buildings and structures depends on several factors, the most important of which are the meteorological properties of the wind, type of exposure and the aerodynamic and mechanical characteristics of the structure.

All buildings have a fundamental frequency of vibration, 10 hertz for one Storey building, 2 hertz for a three stories building, 0.5 to 1 for tall buildings (10 to 20 stories high), and 0.17 hertz for skyscrapers to handle a large swaying motion.

\section{ALONG AND ACROSS WIND}

When the response of building is studied in the direction of wind it is called along wind response. The response of the building in a direction perpendicular to the wind is called across wind response.

Tall buildings will essentially respond in both along and across wind directions. However, which one will be dominant over the other will depend upon the structural characteristics, dimensions and damping. Determining the along wind response is better understood and thus less uncertainty while across-wind is largely empirical and requires wind tunnel experiments.

After some formulations of charts has been done, across wind response can also be determined theoretically by using international codes of practice such as the Indian, Australian and American codes.

\section{DYNAMIC ANALYSIS}

1. For moment resisting frames without bracing or shear walls for resisting the lateral loads

$$
\mathbf{T}=\mathbf{0 . 1 n}
$$

storey's.

Where, $n=$ no. of storey's including basement

for all other building

$$
\mathbf{T}=\frac{0.09 H}{\sqrt{d}}
$$

\section{DESIGN WIND SPEED (VZ)}

$\mathrm{Vz}$ at any height $\mathrm{z}$, for the chosen structure calculated as

$$
\mathrm{Vz}=\mathrm{Vb} \mathrm{k} 1 \mathrm{k} 2 \mathrm{k} 3 \mathrm{k} 4
$$

\section{TURBULENCE INTENSITY}

Turbulent intensity variations with height for different terrains can be obtained using the relations given below :

Terrain category $1:-$ Iz, $1=0.3507-0.3507 \log 10$ $\left(\frac{z}{z 0,1}\right)$

Terrain category $2:-\mathrm{Iz}, 2=\frac{\mathrm{Iz}, 1+1}{\mathrm{Iz}, 4-\mathrm{Iz}, 1}$

Terrain category $3:-\mathrm{Iz}, 3=\frac{\mathrm{Iz}, 1+1}{7(\mathrm{Iz}, 4-\mathrm{Iz}, 1)}$

Terrain category $4:-\mathrm{Iz}, 4=0.466-0.1358 \log 10\left(\frac{z}{z 0,4}\right)$

\section{CROSS-WIND FORCE}

SPECTRUM COEFFICIENT $\left(C_{F S}\right)$

$\log _{10} C_{f s}=A_{1} V_{n}^{4}+A_{2} V_{n}{ }^{3}+A_{3} V_{n}{ }^{2}+A_{4} V_{n}+A_{5}$ ......eq

$\log 10 C_{f s}={ }_{(A} V_{n}^{4}+A_{3} V_{n}^{2}+A_{5) /(} 1+A_{2} V_{n}^{4}+$ $A_{4} V_{n}^{2}$ ) $\quad \ldots . .$. eq

The constants $A_{1}, A_{2} \ldots A_{5}$ are as given in Table and plot of $C_{f s}$ in figure by draft code CED37(7792) 
Table: Values of constants to be used in equation of

\begin{tabular}{|c|c|c|c|c|c|c|c|}
\hline $\begin{array}{l}\text { Aspect } \\
\text { ratio } \\
h: b: d\end{array}$ & $\begin{array}{c}I h \\
\text { at } \\
2 h / \\
3\end{array}$ & $A_{1}$ & $A_{2}$ & $A_{3}$ & $A_{4}$ & $A_{5}$ & Equation \\
\hline \multirow[t]{2}{*}{$3: 1: 1$} & 0.12 & 0.000353 & -0.0134 & 0.15 & -0.345 & -3.109 & \multirow[t]{6}{*}{$(3.4 .1)$} \\
\hline & 0.20 & 0.00008 & -0.0028 & 0.0199 & 0.13 & -2.985 & \\
\hline \multirow[t]{2}{*}{$6: 1: 1$} & 0.12 & 0.000406 & -0.0165 & 0.201 & -0.603 & -2.76 & \\
\hline & 0.20 & 0.000334 & -0.0125 & 0.141 & -0.384 & -2.36 & \\
\hline \multirow[t]{2}{*}{$6: 1: 2$} & 0.12 & 0 & 0.000457 & -0.0226 & 0.396 & -4.093 & \\
\hline & 0.20 & 0 & 0.00038 & -0.0197 & 0.363 & -3.82 & \\
\hline \multirow[t]{2}{*}{$6: 2: 1$} & 0.12 & -0.00039 & 0.000123 & 0.0683 & -0.02 & -3.2 & \multirow[t]{2}{*}{$(3.4 .2)$} \\
\hline & 0.20 & -0.00037 & 0.000124 & 0.0637 & -0.02 & -3.0 & \\
\hline
\end{tabular}

The Reduced Velocity $\left(V_{n}\right)$ can be calculated as follows :

$$
V_{n}=\frac{V_{z}}{f_{0} b\left(1+g_{v} I_{h}\right)}
$$

$\mathrm{E}=\mathrm{a}$ coefficient whose value is $(\pi / 4)$ times the spectrum of turbulence in the approaching wind stream, given as follows :

$$
\begin{array}{ll}
\operatorname{g}_{\mathrm{R}}=\underset{\text { pactor }}{\text { for }} & E=\frac{\pi N}{\left(1+70 N^{2}\right)^{5 / 6}} \\
& \\
& g_{R}=\sqrt{\left[2 \log _{\mathrm{e}}\left(3600 \mathrm{f}_{0}\right)\right.}
\end{array}
$$

$\mathrm{g}_{\mathrm{v}}=$ peak factor for the upwind velocity fluctuations, which shall be taken as 3.5

$\mathrm{N}=$ reduced frequency

$$
=\mathrm{f}_{0} \mathrm{~L}_{\mathrm{h}}\left[1+\left(\mathrm{g}_{\mathrm{v}} \mathrm{l}_{\mathrm{h}}\right)\right] / \mathrm{V}_{\mathrm{h}}
$$

\section{DYNAMIC RESPONSE FACTOR (CDYN)}

$$
C_{d y n}=1.5 g_{R}\left(\frac{b}{d}\right) \frac{K_{m}}{\left(1+g_{v} I_{h}\right)^{2}}\left(\frac{z}{h}\right)^{k} \sqrt{\frac{\pi C_{t a}}{\beta}}
$$

$\mathrm{S}=$ size reduction factor given as follows :

$$
S=\frac{1}{\left[1+\frac{4 f_{0} h\left(1+g_{v} l_{n}\right)}{V_{n}}\right]\left[1+\frac{4 f_{0} b_{0 n}\left(1+g_{v} I_{n}\right)}{V_{n}}\right]}
$$

$\mathrm{L}_{\mathrm{h}}=$ measure of the integral turbulence length scale at height

$$
\mathrm{h}=100(\mathrm{~h} / 10)^{0.25}
$$

resonant response (1 hour period) given by:

$$
W_{e}(z)=0.6\left[V_{h}\right]^{2} d C_{d y n}
$$

\section{EQUIVALENT STATIC WIND} FORCE

The equivalent cross-wind static force per unit height (We) as a function of $\mathrm{z}$ in Newton per meter height, shall be as follows:

where $\mathrm{d}=$ Lateral dimension of the structure parallel to the wind stream

\section{CROSS-WIND BASE OVERTURNING MOMENT}

The cross-wind base overturning moment (M0) in Newton - meters is given by:

$$
M_{0}=0.5 g_{R} b\left[\frac{0.6\left(V_{z}\right)^{2}}{\left(1+g_{v} I_{h}\right)^{2}}\right] h^{2}\left(\frac{3}{k+2}\right) K_{m} \sqrt{\frac{\pi C_{t_{p}}}{\beta}}
$$

where the value is the mode shape correction factor for
overturning momen $\left(\frac{3}{k+2}\right) K_{m}$ )ase 
Table : Damping coefficient [Clause 9.1] CED-37 (7792)

\begin{tabular}{|c|c|}
\hline NATURE OF STRUCTURE & DAMPING COEFFICIENT $(\beta)$ \\
\hline Welded Steel Structure & 0.010 \\
\hline Bolted Steel Structure & 0.020 \\
\hline Reinforced/pre-stressed concrete & 0.020 \\
\hline
\end{tabular}

\section{Equivalent static wind force}

$$
W_{\mathrm{e}}(\mathrm{z})=0.6\left[V_{h}\right]^{2} d C_{d y n}
$$

\begin{tabular}{|c|c|c|c|c|c|c|}
\hline $\begin{array}{l}\text { SR. } \\
\text { No. }\end{array}$ & HEIGHI(m) & $\mathrm{V}_{2}$ & $\mathrm{~V}_{n}$ & $\mathrm{C}_{\mathrm{f}}$ & $C_{\text {ton }}$ & $\begin{array}{l}\mathrm{W}_{\mathrm{s}}(\mathrm{z}) \\
(\mathrm{N} / \mathrm{m})\end{array}$ \\
\hline I & 0 & 0 & 0 & 0.000630957 & 0 & 0 \\
\hline 2 & 10 & 39.07726143 & 1.03163483 & 0.00063755 & 0.206978098 & 3792.747051 \\
\hline 3 & 20 & 42.25745154 & 1.115591452 & 0.000638988 & 0.414423147 & 8880.386219 \\
\hline 4 & 30.00 & 44,11774351 & 1.164702928 & 0.000639737 & 0.621998668 & 14527,71408 \\
\hline 5 & 40 & 45.43764166 & 1.199548075 & 0,00064029 & 0.829690166 & 20555.53351 \\
\hline 6 & 50 & 46.4614342 & 1.226576071 & 0.000640732 & 1.037470748 & 26874.61986 \\
\hline 7 & 60.0 & 47.29793361 & 1.248659551 & 0,000641102 & 1.245324062 & 33430.89167 \\
\hline 8 & 70.0 & 48.0051838 & 1.267330867 & 0.00064142 & 1.453239052 & 40187.83214 \\
\hline 9 & 80 & 48.61783177 & 1.283504698 & 0.000641701 & 1.661207697 & 47119.03134 \\
\hline 10 & 90.0 & 49.15822559 & 1.297771027 & 0.000641952 & 1.869223907 & 54204.45341 \\
\hline 11 & 100 & 49.64162432 & 1.310532693 & 0.000642179 & 2.077282883 & 61428.35079 \\
\hline
\end{tabular}

Cross-wind base overturning moment

$$
M_{0}=0.5 g_{R} b\left[\frac{0.6\left(V_{z}\right)^{2}}{\left(1+g_{v} l_{n}\right)^{2}}\right] h^{2}\left(\frac{3}{k+2}\right) K_{m} \sqrt{\frac{\pi C_{f s}}{\beta}}
$$

\begin{tabular}{|l|l|l|l|l|}
\hline SR. NO. & HEIGHT(m) & $\mathrm{V}_{\mathrm{z}}$ & $\mathrm{C}_{\mathrm{dyn}}$ & $\begin{array}{l}\text { Overturning Moment } \\
(\mathbf{N m})\end{array}$ \\
\hline \hline 1 & 0 & 0 & 0 & $\mathbf{0}$ \\
\hline 2 & 10 & 39.07726143 & 0.206978098 & $\mathbf{1 2 6 5 6 7 5 1 1 . 2}$ \\
\hline 3 & 20 & 42.25745154 & 0.414423147 & $\mathbf{1 4 8 0 9 3 0 9 0 . 2}$ \\
\hline 4 & 30.00 & 44.11774351 & 0.621998668 & $\mathbf{1 6 1 4 8 8 4 4}$ \\
\hline 5 & 40 & 45.43764166 & 0.829690166 & $\mathbf{1 7 1 2 9 6 1 1 2 . 6}$ \\
\hline 6 & 50 & 46.4614342 & 1.037470748 & $\mathbf{1 7 9 1 6 4 1 3 2 . 4}$ \\
\hline 7 & 60.0 & 47.29793361 & 1.245324062 & $\mathbf{1 8 5 7 2 7 1 7 6 . 3}$ \\
\hline 8 & 70.0 & 48.0051838 & 1.453239052 & $\mathbf{1 9 1 3 7 0 6 2 9 . 3}$ \\
\hline 9 & 80 & 48.61783177 & 1.661207697 & $\mathbf{1 9 6 3 2 9 2 9 7 . 2}$ \\
\hline 10 & 90.0 & 49.15822559 & 1.869223907 & $\mathbf{2 0 0 7 5 7 2 3 4 . 6}$ \\
\hline 11 & 100 & 49.64162432 & 2.077282883 & $\mathbf{2 0 4 7 6 1 1 6 9 . 3}$ \\
\hline
\end{tabular}

\section{FORCES CAUSING CROSS WIND RESPONSE}

According to revised code of IS 875, Forces causing cross-wind response of tall structures are of three kinds.

\section{(a) Incident turbulence:}

Turbulence In the wind gives rise to fluctuations in wind speeds and directions which in turn produce forces varying with time. The magnitude of the across-wind force (also called as lift) and the pitching moment thus produced would depend on turbulence level, mean wind speed and the angle of attack (angle of wind incidence in elevation). This effect is important for canopy and similar roofs and bridge decks particularly with fast rate of change of the lift and moment coefficients with respect to the angle of attack. Computation of these forces need wind tunnel studies and / or CFD analysis and are outside the scope of this Code.

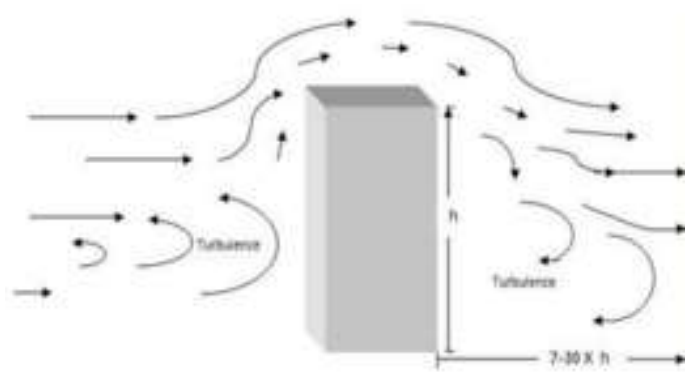

Fig. shows turbulence of wind on building 


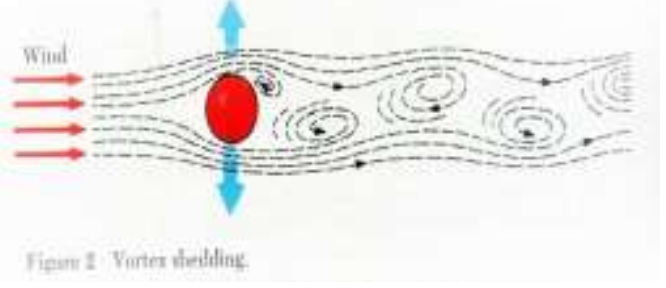

Fig. shows the vortex shedding phenomenon

\section{(b) Cross-wind displacement:}

Mechanisms that may get activated under the cross-wind displacements are of different nature. The excitations under all these mechanisms are dependent on displacement and their derivatives, including rotations. They are named differently depending upon the type of excitation, such as galloping, flutter, lock-in, etc.

All these excitations are also affected by turbulence in the wind. They occurs flexible structures only with damping that is a fraction of $1 \%$ of the critical damping. The analysis of these structures is also beyond the scope of the Draft Code

\section{(c) Wake Excitation:}

It is the type of across-wind excitation and is caused by shedding of the vertices by a structure at regular intervals alternately from its two opposite sides. The periodicity of eddy shedding is defined by Strouhal Number that depends on the shape of crosssection of the structure.

Resonance would result when the frequency of eddy shedding matches the natural frequency of vibration of the structure. This would give rise to large amplitudes of vibration which are limited only by the damping present in the system. In case of high rise structures the wind speed as well as turbulence vary with the depth of structure. The latter is spread over a band of frequencies. For this reason wake excitation includes also the response due to nonresonant frequencies. The CED 37(7792) Code describes the methods of computing the cross-wind response at resonant wind speeds due to wake excitation.

The pattern of this across wind phenomenon is comparatively more regular for circular sections, such as those for chimneys and towers, which can undergo resonant vibrations when the structural frequency matches the forcing frequency. The response is affected significantly by the turbulence content of the wind, and is larger in smoother flows. When buildings attain slender proportions - which may happen for very tall ones, the across wind behavior becomes important.

The theoretical treatment of tall slender structures in the along wind direction is better developed than for the across wind direction, and for this reason it may be advisable to undertake model studies in a wind tunnel for such structures.

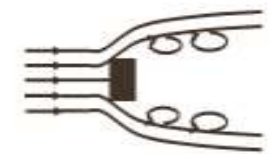

Fow arcund isolated boilding

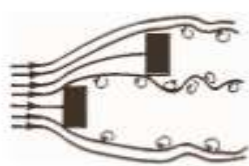

Fow rovend two bulting
Figure 9: Typical siad flow arvund isolated and two nearty buildings

It is observed from the model that when a tall building is located at the edge of the wake shed by another tall building, the value of the interference effects or buffeting factor is the largest. The more the location angle $\varphi$ is away from wake angle, the less the values of the static wake response pDIS, the wake amplification factor $\mu \mathrm{DI}$ and the buffeting factor BF are. When the distance $\mathrm{L}$ between two buildings is beyond certain value, the buffeting factor approximates to unit. In this paper, the influence of the location angle $\varphi$ and the distance L among buildings on the responses of these tall buildings and the corresponding varieties of along-wind and crosswind pressures due to the influence are discussed in detail.

Specifications for wind loads on structures are obtained for idealized wind loading and for structures in a stand-alone situation. However, wind loads experienced in the real situation could be different in varying degrees, to those obtaining in a 'stand-alone' case. The extent of this difference will depend upon the structure type and its surroundings and can be determined only through carefully conducted measurement programs. This is quite possible with modern testing facilities. The vexing part of the problem, though, is that mostly the results are 'case specific' and generalization with any reasonable degree of assurance is possible only when a sufficient large number of experiments are conducted on systematically arranged layout of the structures. This leaves wind tunnel or field measurements as possibly the only way to tackle the problem.

\section{INPUT AND OUTPUT DATAS}

Putting those structures in STAAD pro for carrying out its behaviour against wind loading with the combinations of dead load as well as live load is obtained (where $h$ is the height of building, $b$ is the breadth/dimension, perpendicular to wind direction, $\mathrm{d}$ is the depth/dimension parallel to the wind direction, $\mathrm{TC}$ is the terrain category, $\mathrm{Vb}$ is the basic wind speed in $\mathrm{m} / \mathrm{s}$ ). Whether building contains moment resisting frames or other buildings are 
also to be feed there. Eight buildings were used; two buildings for each h:b:d ratios. Four h:b:d ratios were described for the analytical results of across building which are:

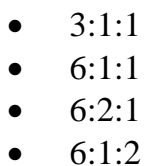

Results are carried out only in terrain category 1 so as to calculate the maximum response of models. Also the basic wind speed is $50 \mathrm{~m} / \mathrm{sec}$ for all the models for studying the maximum phenomenon the building can achieved.

Total 16 results were plotted ( 8 from along wind and 8 from across wind studies) and there variations are shown in this chapter. Excel interprets the calculations of dynamic response with the help of formulations proposed in the Draft CED-37 (7792) with respect to the variation of various inputs. All conditions are prescribed for the designing purpose of rectangular buildings of different $h: b: d$ ratios.

\section{CONCLUSION}

The variation of Shear force and Bending Moment in tall buildings shows that how along and across wind can be calculated analytically with the variation of height, width and depth. After the comparison of Dynamic results using Draft code CED-37 (7792) with STAAD Pro results, following conclusions are drawn:

(1) After studying, Across wind can be finally calculated analytically for four different cases of different $h: b: d$ ratios.

(2) For shear force calculation of tall building for along wind, STAAD Pro can be used with certain precautions.

(3) Overturning moments for along wind in STAAD Pro is also provides safe and sound results.

(4) STAAD Pro results cannot be trusted for Across Wind response, as unexpected variations are takes place.
(5) STAAD Pro, doesn't gives any result and consideration for torsional oscillations due to Across Wind.

(6) For across wind calculations, loadings applied should be more comfortable with the software (if any used).

(7) Thus we conclude that MS Excel is sufficient to provide the result analytically of along as well as across wind response, But STAAD pro can only be used for the along wind response, and in case of across wind response, other soft wares can be used.

\section{REFERENCES}

[1] P.N. Godbole, L.M. Gupta, O.R. Jaiswal, Prem Krishna "STTP on Wind Effects on Structures" VNIT, Nagpur (2005)

[2] Hajra Bodhisata and Godbole P.N. "Along Wind Load on Tall Buildings-Indian Codal Provision". Proceedings of the third National Conference (NCWE-2004), Jadhavpur University, Kolkata, India.

[3] Arvind Y. Vyavahare, Godbole. P.N, Trupti Nikose "INTERNATIONAL JOURNAL OF CIVIL AND STRUCTURAL ENGINEERING "Volume 2, No 3, 2012.

[4] Akshay A. Bendre"Development of Artificial Neural Network for Along Wind Response of Tall Buildings" M-Tech Project, Department of Structural Engineering RKNEC, Nagpur. (2014)

[5] IS: 875(Part3): Wind Loads on Buildings and Structures -Proposed Draft \& Commentary By Dr.Prem Krishna Dr. Krishen Kumar Dr. N.M. Bhandari Department of Civil Engineering Indian Institute of Technology Roorkee

[6] John Holmes, Yukio Tamura, Prem Krishna "Comparison of wind loads calculated by fifteen different codes and standards, for low, medium and high-rise buildings" (2009)

[7] J. Lakshminarsimham, B H Lakshma Gowda, and Ch Sivnnarayna "Interference effects on wind pressures on low rise and high rise square structures in side by side arrangement" (2005)

International Journal of Engineering Research and Applications (IJERA) is UGC approved Journal with S1. No. 4525, Journal no. 47088. Indexed in Cross Ref, Index Copernicus (ICV 80.82), NASA, Ads, Researcher Id Thomson Reuters, DOAJ.

Rohan Singh Parihar. "Development of Software Package in Excel for Along and Across Wind Response of Tall Building." International Journal of Engineering Research and Applications (IJERA) 7.7 (2017): 71-76. 